\title{
AC 2012-4541: LESSONS LEARNED ON PREPARATION, MOTIVATION, EXPECTATION, AND REFLECTION WHILE TEACHING AND MENTOR- ING AS A GRADUATE STUDENT
}

\section{Kacie Caple D’Alessandro, Virginia Tech}

Kacie C. D'Alessandro is currently a Ph.D. candidate in the Structural Engineering and Materials Program of Civil Engineering at Virginia Tech (Blacksburg, Va.). She received both her B.S. and M.S. from Clemson University. Once completing the Ph.D. program at Virginia Tech, D'Alessandro plans to pursue a career in academia to teach and to continue research on concrete structures. She also plans to pursue opportunities with engineering education research and K-12 outreach programs. 
Lessons Learned on Preparation, Motivation, Expectation, and Reflection While Teaching and Mentoring as a Graduate Student 


\begin{abstract}
Leading a course can be either an exciting or a stressful experience, depending on the level of preparation, expectations, and personal motivation expended by an individual. The excitement can come through teaching material that interests you or even through watching students develop an understanding of important concepts. The stress can come through expecting too much or too little, but it can also come if you are not prepared for what is to come. Through the stressful and exciting moments, you can learn a variety of lessons the first time you teach. You can even learn a lot the second time you teach, the third, and so on. Because of this cyclical learning process, reflection can be an essential component to continual improvement. Through my experiences, I've found that preparation, expectation, motivation, and reflection are fundamental elements that contribute to whether someone is left with either a sweet or bitter taste after teaching as a graduate student.
\end{abstract}

This paper will examine lessons learned on preparation, expectation, motivation, and reflection in teaching and mentoring through the experiences and perspective of a graduate student. First, I taught an engineering design course intended for junior and senior level undergraduate students. In this course, I was the primary instructor, managing all classes, exams, and assignments. The following year, I was a part of a team of faculty and graduate students in a freshman engineering program. In retrospect, preparation, expectation, motivation, and reflection played a pivotal role in my professional development along the way. Understanding how to apply these four components to teaching and mentoring should not only help a new graduate student instructor prepare for and enjoy the experience, but it should also help them discover new ways to communicate their interests and excitement to others and reflect on themselves as an instructor and mentor.

\title{
Introduction
}

As in swimming, first-time teachers strive to keep their head above water and maintain control. For graduate students, teaching can cause additional challenges because of the need to make progress on research and toward graduation. While teaching for the first time, these challenges can easily be complicated by a simple lack of experience. Understanding the significance of preparation, motivation, and expectation before entering a teaching appointment can alleviate the tension that would otherwise be expected through this new experience. In order to learn through these elements, reflection can also be a useful tool for educators of all experience levels to evaluate themselves and improve their pedagogy. Altogether, I have found that these four fundamental elements of preparation, motivation, expectation, and reflection have shaped my teaching experiences and have contributed to my overall perceptions of higher education.

This paper will examine lessons learned on preparation, motivation, expectation, and reflection through the experiences and perspective of a graduate student. Using these lessons, suggested tips are presented for graduate student instructors, specifically those teaching for the first time. Understanding how to apply these four components to teaching and mentoring should not only help a new graduate student prepare for and enjoy a new teaching experience, but it should also help them discover new ways to communicate their interests and excitement to others and reflect on themselves as an instructor and mentor. First, the paper will provide a summary of my 
training and teaching experience as a graduate student. Following, the paper will present lessons learned on the four components: preparation, motivation, expectation, and reflection. These sections will also provide suggested tips for graduate students teaching for the first time. Finally, a brief charge to graduate students planning to teach will be presented, providing some final words of encouragement for those venturing into the unfamiliar world of teaching.

\section{Background}

Before focusing on the four components of preparation, motivation, expectation, and reflection, it is necessary for you as the reader to know my training and teaching background. Throughout this section, these four areas will be briefly mentioned. However, a more in-depth look at each of these components will be discussed in later sections.

\section{Supplemental Instruction Leader}

The Supplemental Instruction (SI) program ${ }^{[1]}$ supported by the Academic Success Center at Clemson University was one of the first motivating factors leading me toward a future career in academia. In this program, undergraduate students led three one-hour study sessions per week for a course they had successfully earned an " $\mathrm{A}$ " average in during a previous semester. The sessions typically consisted of additional practice problems and activities for students in the course. The SI Leaders attended class with the students, allowing the sessions to be tailored to the material presented in that individual section. Leaders also had regular meetings with the course instructor to discuss the progress of sessions and information pertaining to future coursework. Leaders were required to undergo training prior to the start of the semester. In the training sessions, I was introduced to the Socratic method ${ }^{[2]}$ of questioning to facilitate learning. All SI Leaders were encouraged to use this form of questioning in the study sessions to lead students to discover answers using their current level of knowledge. In my current teaching, I continue to use this form of questioning with students, and I believe this training was useful in developing what has now become habit to me. Leaders were also given information on study skills to mentor students on good study practices during the sessions. As encouraged by the SI staff, I prepared and administered practice assessments, including quizzes and exams, for the students participating in my sessions. In this program, I was a SI Leader for Calculus I and Engineering Mechanics: Statics during the 2003-2004 academic year. This experience provided me with an opportunity to gain confidence leading a group, to practice preparing lesson plans, and to learn valuable skills in communicating with and mentoring students. Overall, I believe this opportunity laid the foundation for my development as an educator.

\section{Instructor for Reinforced Concrete Design}

In 2009, while enrolled in the structural engineering doctorate program at Virginia Polytechnic Institute and State University (Virginia Tech), I was accepted into the CEE Academic Preparation Program within the Charles E. Via, Jr. Department of Civil and Environmental Engineering ${ }^{[3]}$, allowing me to teach a course as a graduate student. In this program, I was assigned as the instructor for Reinforced Concrete Design I under the mentorship of a faculty member who typically taught the course. I was assigned this role approximately one month in advance of the first day of classes, and approximately 40 students were enrolled in my section of 
the course. I was responsible for all activities associated with the course, including: preparation of course material, instruction of course material, providing office hours, maintaining a course website, development of homework assignments, and the design and grading of exams. Although I developed the homework assignments, I was fortunately assigned a grader who was responsible for grading all homework assignments. I provided the grader with an answer key, and I gave some basic instruction on how to grade the assignments. While teaching this course, I developed interactive skeletal notes to be presented using a document camera after first using PowerPoint presentations and the chalk board to provide class notes. Think-pair-share and collaborative learning activities were integrated during the second half of the course. Frequent in-class surveys were also used to gather feedback from students. This information allowed me to better reflect on my instruction of the course and assessment design, allowing me to evaluate myself and improve my pedagogy.

\section{Instructor and Workshop Leader in First-Year Engineering Program}

In the 2010-2011 academic year, I was offered an appointment to teach in the freshman engineering program through a partnership with my home department. In fall of 2010, I taught the first-semester engineering course, Exploration of Engineering Design, offered to all first-year engineering students at Virginia Tech. This course was designed for students to attend one 50minute lecture and one 110-minute workshop each week. I team-taught a lecture of this course along with a faculty member in the Department of Engineering Education ${ }^{[4]}$, and I led one workshop section. The faculty member teamed with me for the lecture also served as my faculty mentor during this teaching assignment. Approximately 70 students were enrolled in our lecture section, and approximately 30 of these 70 students were in my workshop section. In this course, a variety of different topics in engineering were introduced weekly, with the exception of a fiveweek programming module. Since multiple instructors teaching the same material in separate lecture sections prepared common exams for the course, common notes were prepared for all instructors to distribute material using Tablet PCs and DyKnow ${ }_{\mathrm{TM}}$, software used as a technological teaching tool. In preparation for this course, all workshop leaders and instructors were given a tutorial on using DyKnow ${ }_{\mathrm{TM}}$ in the classroom to interact with students virtually. Using DyKnow ${ }_{\mathrm{TM}}$, I was able to receive instant feedback from students on their level of understanding, poll students for answers to multiple choice questions, collect student work, and display student work as a teaching aid during class. Although common notes were prepared for the course, instructors were given the freedom to alter the course notes or integrate relevant examples from their own work, as long as they maintain the integrity of the notes for the students. I decided to take advantage of this opportunity to integrate several of my own personal examples from past projects and research.

In spring of 2011, I led two 110-minute workshop sections for the second-semester freshman engineering course, Engineering Exploration. Each section contained approximately 35 students. This course provided opportunities for students to delve further into the engineering design process through focusing on specific elements of engineering design and concluding with a semester project. In this course, my role shifted from an instructor to a mentor and facilitator because of the focus on engineering design. Again, I integrated examples from my experience and research into the classroom through both teaching and mentoring. 
All of these experiences form the framework for the ultimate purpose of this paper: to provide a resource for new graduate student instructors. Derived from my experiences, I focus on what I have learned based on four main themes: preparation, motivation, expectation, and reflection.

\section{Lessons on Preparation}

As a graduate student teaching for the first time, it seems there is little time to prepare for teaching a course. However, it is important to make the most of what time you have to prepare in between your own courses, research, and writing reports. Without proper preparation, you make yourself vulnerable to late nights, coffee addictions, and possible embarrassment in the classroom. In particular, if you are teaching a course as the primary instructor, it is essential to prepare as much as you can prior to the beginning of the semester. You not only owe this to yourself, but also to the students enrolled in the course. As an instructor, it is essential for you to know the responsibility you have to the students. You are responsible for providing them with knowledge essential for their success in future courses and their future careers. For this reason, I consider preparation one of the most essential elements to effective teaching. Without preparation, there is no execution. In this section, I discuss lessons I have learned in preparing for a course, particularly focusing on preparing as the primary instructor.

\section{Training Opportunities}

During fall of 2009, I began taking courses through the Engineering Education Graduate

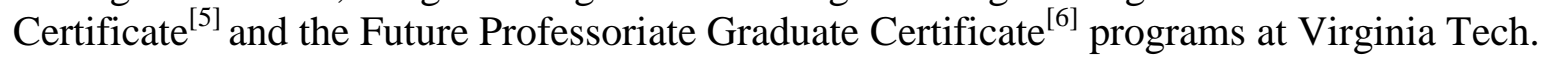
These programs are designed to prepare graduate students for a future career in academia by examining topics in higher education. I found these courses very helpful in preparing me for teaching and mentoring. Since I was teaching while taking some of these courses, I was able to immediately integrate some of this new knowledge into the classroom. If you are passionate about becoming an effective teacher, seek out opportunities to learn about practical methods of managing a course, from assessment design to teaching practices in the classroom. If you do not have access to courses in higher education, seek out advice from faculty members you respect. In my case, I wish I had taken these courses prior to leading my first course. I was fortunate to integrate new pedagogical methods as I taught reinforced concrete design, but it would have been beneficial for me to have prepared for this prior to my teaching assignment.

Even after teaching my first course, I continue to seek out new opportunities to learn about technological teaching tools and innovative pedagogy. For instance, I have taken part in programs available for faculty and graduate students at Virginia Tech through the Faculty Development Institute (FDI) ${ }^{[7]}$ to learn new technology and teaching tools. Having taken advantage of a variety of opportunities to learn about technology and innovative pedagogical methods, I also discovered new methods to make the planning and preparation processes more efficient.

\section{Logistics of Preparing a Course}

My faculty mentor was extremely helpful and supportive when I structured my first course. Since my mentor had taught this course before, I was privy to her resources. I spoke to my 
mentor about the course structure, and I also compared similar materials from other instructors of the same course. In my case, the objectives were already prepared for each course I taught because they were established by the department. If this is not your case, consult with an instructor who has taught the course before, or evaluate what students should be able to demonstrate or understand once they have completed the course ${ }^{[8,9]}$. Objectives can define the content of a course by identifying specific learning outcomes of students. Focusing on these objectives when preparing the content and assessments can provide consistency in the course through what has been identified as the most important aspects of the course ${ }^{[8,9]}$. With the objectives established, you can focus your efforts on logistics and course content.

I consider logistics for a course to include pedagogy and items commonly communicated through a course syllabus, including: types of assessments, weighting of assessment categories, required materials, and general course policies. To help determine logistics, I have provided a list of questions that helped me begin planning my first course:

- How will you pass on information to students? Will you use structured notes, class discussions, or some other method?

- Will you provide a structured schedule for the course material?

- What types of assessments will you design for students to demonstrate their knowledge and understanding?

- How frequent will these assessments be administered?

- How will these assessments be weighted in comparison to one another? In what areas of assessment do you want students to focus their efforts?

- Will you require any guidelines for completing or submitting assessments?

- Will you require students to have specific materials, including textbooks?

- Will you provide guidelines for proper etiquette in your classroom? These guidelines may pertain to the use or misuse of items, including: food, drink, laptops, writing utensils, or hats.

- Are there any policies required by your institution to be observed and enforced in the classroom? For example, does your institution have a defined honor code policy?

Finally, I learned that the content of any course requires extensive planning and preparation. For the first course I taught, I had access to notes from two different instructors. To develop my course notes, I referenced these materials and the required textbook for the course. In some ways, this was helpful because each resource provided a slightly different presentation of the same material in varying degrees of detail. This method was also very time-consuming because I examined three different resources. For graduate students, time is often a precious commodity. I originally thought my thorough examination of these resources would help me prepare better notes. In retrospect, it was only useful to examine all resources in very few cases; otherwise, I spent more time than necessary preparing for a topic. I learned that I should be very careful to use my time and resources effectively when preparing for class because my research progress suffered as a result of time-consuming preparation. 


\section{Preparations for Day 1}

Preparing for the first day of class is necessary for instructors of all experience levels. Prior to the first day of class, I found it useful to visit the classroom and practice using any equipment available in the class. For instance, I prefer to use a document camera and my laptop in the classroom. For this reason, I always make sure I can connect to the projection system in a classroom before I teach on the first day. When using technology, unexpected errors are common, and it is essential to be prepared in case of malfunctioning technology. Although errors often result in a negative outcome, I experienced an error that changed the layout of my course notes for the better while teaching reinforced concrete design. I had prepared skeletal notes that were intended to be presented using a PowerPoint presentation. After having difficulties connecting my computer to the projection system, I decided to complete the notes on an extra copy of the student version using the document camera. Through this experience, I learned that I had not allowed enough space in the notes for students to write their responses. I also learned that it was much easier to connect with students using the document camera. I had freedom to interchange documents easily, and students could easily follow along as I physically completed the notes with them. This problem actually resulted in a positive change because I was fortunate to have a back-up plan. Even when not using technology, it can be advantageous to practice using chalkboards and dry-erase boards in the classroom prior to teaching. Practice writing, and walk around the room to make sure students will be able to read the writing from all seating areas.

Forming a structured plan for the first day of class is necessary for a new instructor. On the first day, it will be important to properly introduce yourself and the course. In my case, I typically introduce myself, provide a brief overview of the course, and discuss the syllabus. Following, I go through the class roster, asking each student to give me their preferred name. If time permits, I have asked students to provide additional information about themselves, such as a favorite hobby or what they did over the most recent break. Knowing more information about students helps me learn their names.

In the first class I taught, I decided to keep the first day very simple by only going through introductions and the syllabus. In retrospect, I believe it would have been more beneficial to extend the introductions or begin the course material that first day because I only utilized half the class period. While teaching in the freshman engineering program, I decided to incorporate a goal setting activity on the first day after seeing this done in another class. Later in the term, I asked students to revisit their goals after specific course milestones. I have also taken time during my introduction to explain to students that I am planning to be a faculty member in the future. Because of this, I clearly state that I am open to their comments and suggestions about how I can improve my teaching methods and make the course better for them. With whatever plan you decide for the first day of class, it can be very useful to have an agenda to keep you on track (Figure 1). You may also want to set time constraints for these activities to manage class time effectively. 


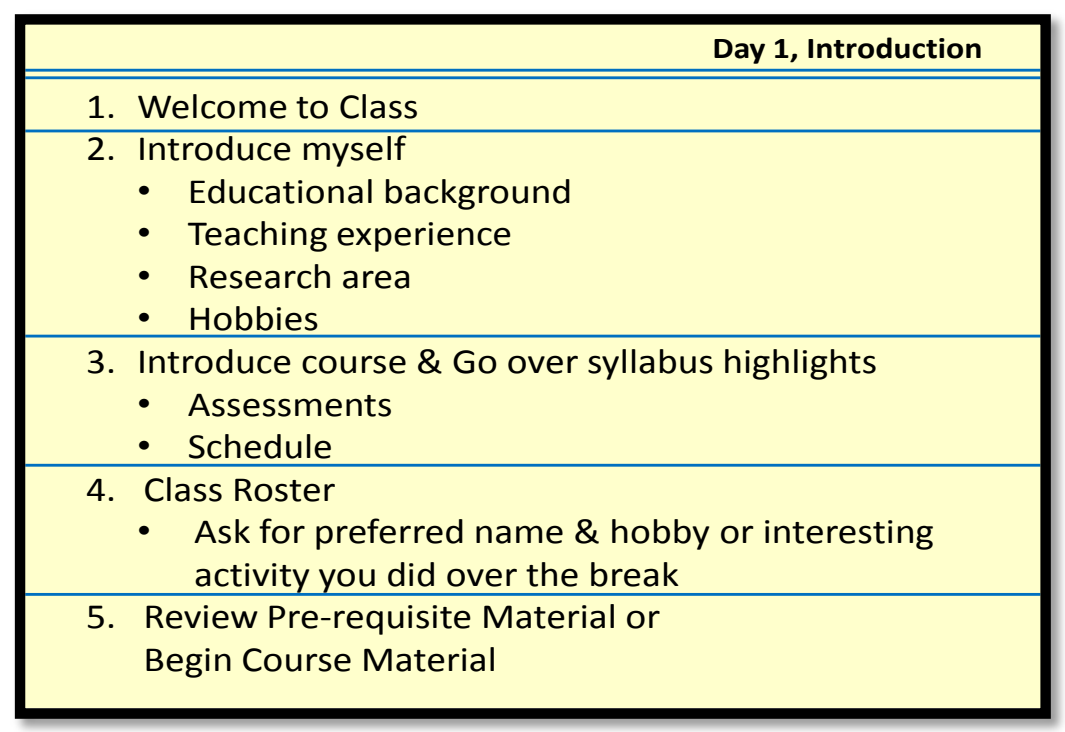

Figure 1: A brief sample agenda for the first day of class.

\section{Establishing a Learning Atmosphere}

Through my experience, I learned that it is also important to establish the classroom learning atmosphere within the first week of classes ${ }^{[10]}$. When I taught concrete design, I was primarily concerned with providing students with the necessary information to accomplish the objectives. The learning environment established was knowledge-centered ${ }^{[11]}$ as I focused primarily on students meeting the objectives of the course. The class was originally arranged as a lecturebased environment. As I later attempted to integrate active learning activities ${ }^{[12]}$ through collaborative learning mid-semester, students were reluctant to the change. In the freshman engineering program, I made an effort to integrate active learning during lectures by encouraging students to take part in class discussions starting on the first day of class. Fortunately, group activities were often integrated into each workshop, making interaction in class a priority starting on the first day.

\section{Time Management in Class}

Time management in class is a constant area of improvement for me. I tend to go into more detail on topics that spark my interest. For this reason, I had to learn to prepare for class with time management in mind. As the semester progressed, I became better at managing my time in the classroom for reinforced concrete design, but this is still something I can continue to improve. While teaching in the freshman engineering program, multiple sections were required to teach the same material. Therefore, I had to make sure I stayed on a schedule to finish what was required for that day. Often times, the instructors were supplied with a suggested time allotment for each item on an agenda for that day. However, when I included additional examples from my research and experience, I had to be sure these examples would fit within the class period. This experience was very helpful in teaching me time management skills associated with managing multiple activities within a set time constraint. 


\section{Recovering from Mistakes}

Through my teaching experiences, I have also learned that I must be mentally prepared to turn mistakes into learning experiences. While teaching reinforced concrete design, I prepared skeletal course notes for the majority of the term. I had several minor typing errors, but the most memorable error I made was not in typing, but in calculations. I had prepared an example on shear design of beams several days before I presented it in class, and I remember that I neglected to take time to carefully double check the calculations. I worked through the first part of the example with the class before asking students to work on the remaining parts in class. After students completed the next part of the example, I realized I had made an error in my previous calculations that greatly affected the proceeding solution. We had already worked through the majority of the class time on this example, and I was distraught that I had made such a grievous calculation error that complicated the solution. I explained my error to the class, and the students appeared to be disappointed, as well. I made a quick decision to correct my mistake outside of class and revisit the example in our next session. In the remaining minutes of class, I began introducing the next topic in the course. Whether or not this was the best decision, I knew we all needed a fresh start on that example after the error was made known. I learned through this experience that I must be mentally prepared to handle my mistakes and learn from them. Although I do my best to avoid mistakes, I must remember that errors are to be expected because I am human. I cannot allow stress to rule me when I make a mistake. Rather, I must make amends by fixing the mistake and moving on from that point. In this experience, I was also reminded of the importance of double checking my calculations.

\section{Emergency Absences}

Finally, I want to address the dreaded emergency absence. Family emergencies and illnesses are unpredictable. To avoid additional stress during this time, I have learned that instructors must be prepared in case of an emergency absence. In general, I encourage graduate student instructors to have materials prepared one to two weeks in advance. In my case, I was not prepared when a family emergency occurred during the first semester I taught. I was fortunate to have several graduate students previously offer to teach my course if I was ever unable to be in class. After arranging for a replacement, I had to quickly finalize the notes because I was not fully prepared for the new lessons. Although it may be acceptable to stay one step ahead of the students at times, it is important to remember that unexpected events may require you to find a replacement for multiple class sessions with very little notice. In this case, I believe it is best to be prepared with a replacement in mind. Also, having materials readily available for a substitute instructor could potentially help to alleviate stress during an emergency absence.

\section{Summary of Preparation Tips}

Preparation is definitely an area I have learned a lot about through teaching. In fact, this is most likely the area I have spent the most time on during my teaching appointments. Because there were many lessons I learned in preparation, I have summarized these as a set of tips for graduate students: 
1. Take advantage of training opportunities to learn about pedagogical methods and managing a course.

2. If you are not assigned a faculty mentor, seek out a faculty member you respect to discuss teaching techniques and course logistics.

3. Plan each class session with time management in mind, and prepare an agenda to stay on track with each class session.

4. Use your time and resources effectively to prepare for teaching, to design and grade assessments, and to make progress on your research projects.

5. Visit the classroom prior to teaching on the first day, and practice using the equipment in the room, from technological systems to basic writing boards.

6. Always have a back-up plan for technology.

7. Be prepared to establish the learning atmosphere within the first week of classes.

8. Be mentally prepared to turn mistakes into learning experiences and to formulate quick decisions.

9. Always double check handouts and calculations.

10. Be prepared with class materials at least two weeks in advance in case of an emergency absence.

\section{Lessons on Motivation}

\section{Discovering Personal Motivation}

Motivation can directly influence initial and final perspectives of a teaching experience ${ }^{[13]}$. I learned that both intrinsic motivation and altruistic motivation ${ }^{[13]}$ were the driving forces keeping me energized while teaching. Not every day ended on a positive note. For example, the day I realized I had a calculation error in my shear design example was not a highlight I wish to revisit often. I left class feeling somewhat defeated, but I had to find a reason to come back to class the next day. I remembered my responsibility to the group of students I was teaching. I also remembered why I was placed in that teaching position. I wanted to gain experience for a future position as a faculty member. Through this experience, I discovered motivation beyond simple obligation. I enjoyed interacting with students, leading them to discover solutions, and sharing my knowledge, experience, and interests with them. My personal motivation is driven by my desire to serve through teaching.

For the graduate student teaching for the first time, motivation is something I encourage you to seek and discover about yourself before teaching. You may find that you are extrinsically motivated ${ }^{[13]}$ simply because this teaching appointment provides you with funding. If this is the case, I urge you to consider the role you will play in the education of your students. Consider the responsibility that you have to the students, and also consider the influence you may have in their education. Finally, reevaluate your motivation mid-way through your teaching appointment and again at the end. You may find that your motivation has been shaped by the experience.

\section{Influencing Student Motivation}

Student motivation is a completely different beast to conquer. I had high hopes that students would be motivated by learning engineering. Based on my observations, I noticed that many 
students were highly motivated by grades. These students were primarily concerned with how to receive a specific number of points on an assignment. I did, however, have some students who were motivated to learn for their future careers. For example, some student studying construction told me that they were excited to learn the basics of reinforced concrete design. They wanted to be familiar with the proper terminology to communicate with engineers and the reasoning for design standards. Even though they did not intend to design reinforced concrete structures, these students were interested in how the course content could be used in their future careers. This experience made me realize first-hand that one of the best ways to motivate students was to increase the utility value of a task by directly addressing the relevance to their future career ${ }^{[14]}$. Ultimately, students want to see that what they are learning is worth the effort. Application is a great way to communicate engineering concepts, but I had not taken much care in explaining the relevance of the material I was teaching. From this point on, I made a point to address relevance and application. I decided to learn more about the career goals of my students, and I planned to integrate relevant examples into class and homework assignments directly pertaining to these career goals. This learner-centered approach placed students at the forefront of the learning process, allowing them to directly influence the course content ${ }^{[11]}$. This experience taught me that my pedagogy could directly influence the motivation of students.

In addition to relating material to student career goals, I share my personal experiences with students as it pertains to course material. Students have shared that they have benefited from these examples based on my experience in extra-curricular engineering activities and research. Particularly in the freshman engineering program, I wanted to share with students how the material they were learning in the course could be used for more advanced applications in engineering. Students shared that these examples helped them better understand how engineers use the tools they were learning. Knowing an application to these tools seemed to boost their intrinsic motivation as their interest in the examples encouraged them to learn the concepts and skills required of them ${ }^{[14]}$.

Through these experiences, I have learned that it is also important for the graduate student instructor to consider how they can motivate their students beyond the need for simply earning a particular grade. Not only will this be of use to the students, but I believe motivated students are more likely to generate a positive experience for the instructor. As a graduate student currently in the education system, you may be able to more easily connect to the needs of students. Consider how you may be more motivated if you were a student in your own class, or ask students to give you feedback on how you can make the course more interesting to them to boost their intrinsic motivation ${ }^{[14]}$.

\section{Lessons on Expectation}

\section{Instructor Expectations}

Expectations are another factor that can affect your final perception of a teaching experience. Knowing exactly what to expect is impossible. However, if you broaden your expectations and do a little research on the course you are teaching, you may be able to better formulate expectations. When I first taught, I expected to spend much less time in preparation for lectures than I did. However, the format of my skeletal notes required more preparation time than 
originally intended. I expected students would come to my office hours for help when they did not understand the material. This was true in some cases, but some students were still reluctant to seek help. I expected that grading would take much less time than it did in actuality, and I naively expected students would hear my announcements in class. I also expected that students would enjoy group activities, but I was proven wrong when students were reluctant to work together in class.

I formed a lot of expectations based on my experiences in school and from accounts of other graduate students teaching in my department. The graduate students warned me that teaching would consume the majority of my time, but I was naïve to the severity of their warning. I originally thought I would have ample time to spend on my research while I was teaching. I had thought through the timeline of my day, and I decided that I would only spend certain days and times on teaching activities. However, I neglected to consider the time necessary to answer emails from students, to design and redesign assessments, to grade and record grades of over 40 exams, and to do everyday tasks, such as making copies. Before the end of my first semester teaching, I had become more efficient at preparing for class, designing assessments, and grading. However, learning how to do these tasks efficiently took time and practice.

To make grading more efficient, I learned that pre-assigning a value to each part of a multi-step question was very useful (Figure 2). It took some time to think through point allocations in some cases, but this process saved time during grading overall. Despite this grading plan, some students still surprised me with unexpected methods or solutions, nullifying the original pointby-point process. In these cases, I had to use my best judgment to fully examine the solution for possible merit.

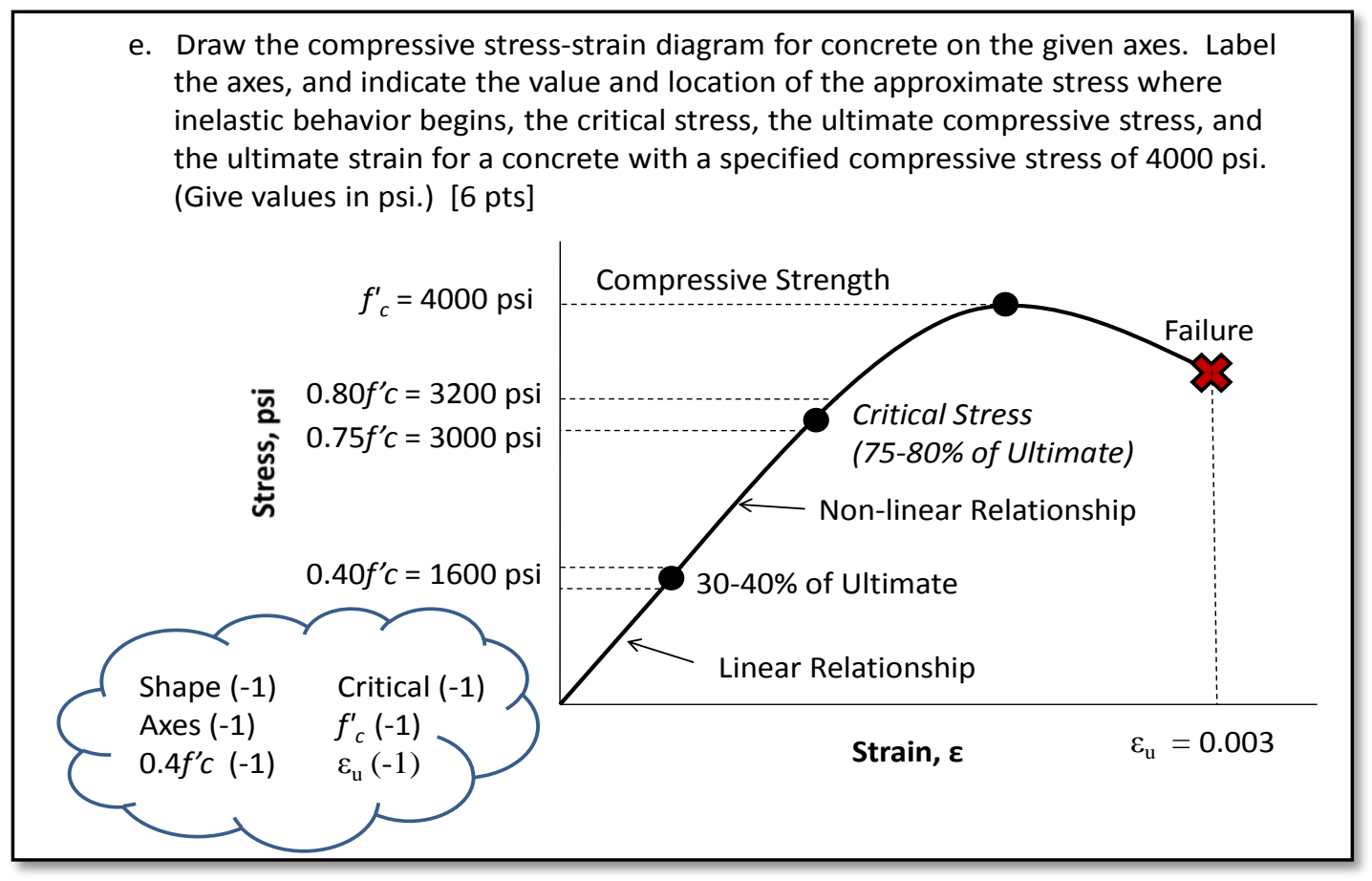

Figure 2: Sample of pre-allocating points within a multi-step problem. 
While team teaching in the freshman engineering program, I took part in designing exams. Each member of the faculty team submitted multiple questions, and the course coordinators selected questions from those submitted to form a draft exam. As a group, we reviewed the selected questions to make sure each course section had an equal opportunity on the common exam. Through this experience, I learned a lot about formulating questions. Specifically, I learned the need to consider what terminology students know and do not know when designing an exam question. One of the questions I designed on one of these exams used the term "cross-section" in the description of an object. However, not all first-year students were unfamiliar with this term before this exam. I did not expect the students would be unfamiliar with this terminology because I was very familiar with using this term on a day-to-day basis. Therefore, when designing assessments, it is very important to consider what terminology a group of students do and do not know. You cannot expect to be correct every time, but you should use your best judgment when you assume certain expectations of students. For this reason, it can be advantageous to learn about the current level of knowledge of your students.

\section{Student Expectations}

Not only do instructors have expectations, but students also have expectations of a course and instructors. In my experience, students often expected to find a way to use as little effort in a course as possible to reach a desired grade. Some students expected to have an end-of-course redemption policy that would make-up for their lack of commitment during the entire semester. Still other students expected the course to be difficult and made efforts early on to seek guidance and help from me before they found themselves sinking in a sea of confusion. Whatever the case may be for students, I have learned it is best to tell students what they might expect from a course and what I expect of them. I do not sugar coat difficult material. Rather, I want students to know that certain aspects of a course have been historically challenging so that they are prepared to put forth the proper amount of effort. I also prefer to directly communicate my expectations of students, clearly explaining the reasons for these expectations. I expect students to use their best efforts, to present their work neatly, and to seek help from me when they have difficulties. These expectations are set in order to begin preparing them for a professional career in engineering. I believe this open communication about expectations is important to establish some structure and guidance for students.

\section{Forming Expectations}

If you want to be more aware of what to expect, consult faculty members you trust to learn from their experiences. If you can find a faculty member with a similar teaching style or philosophy, you can also receive valuable tips from them on what to expect while teaching. Graduate students who have either taught the same course or at least a course in a similar department are also great resources to learn about what to expect. In any case, do your research before making assumptions and formulating expectations. Finally, if you have certain expectations for your students, you should consider communicating these directly to students on the first day or outline these in the course syllabus. 


\section{Lessons on Reflection}

\section{Journaling}

When I began teaching, reflection was not something I had intentionally decided to do. However, while taking courses on pedagogy and practicum in the classroom, I learned several useful methods to reflect on my teaching. One of the most useful means of reflection I used involved journaling. I began writing at least once a week on activities associated with the course. I focused primarily on pedagogical methods in the classroom, assessments, and out-ofclass planning and preparation. These journal entries were useful as I evaluated how students responded to certain activities over time. They were also useful as I documented my planning and preparation methods. Although I am not an avid journal writer outside of teaching, I found this to be a very helpful method in documenting my progress in teaching. I encourage new instructors to use journaling as a means of reflection and self-evaluation. Entries can be quickly composed directly following a class session. Additionally, notes can be made in the margins of course notes to inform you of how students may have responded to a particular topic or activity, specifically noting areas in need of improvement or areas of success.

\section{Faculty Mentor and Peer Evaluations}

Since I had faculty mentors in two of the courses I taught, I also used teaching evaluations from these faculty members as a means of reflection. It was helpful to receive feedback from faculty members who regularly teach the same courses I was teaching. If you do not have an assigned faculty mentor, consider inviting faculty members or fellow graduate students you trust to visit your classroom to give you feedback. You should also plan to meet with that person shortly after your class releases. I have found that it helps to discuss a specific day directly after class. Otherwise, it is easy to forget what exactly occurred on that day.

\section{Gathering Student Feedback}

Finally, I integrated short in-class evaluations, or surveys, to learn about student perceptions of my pedagogy and to better reflect on the course. Topics I targeted included assessments and perceptions of the course and the instructor. I also asked them for suggestions and general thoughts on recent lectures (Figure 3). These fairly short evaluations completed at the end of class were a great way for me to receive instant feedback from students. They were submitted anonymously, making it more appealing to students who would not normally talk to me about the course face-to-face. Minute papers can also be another means of gaining quick feedback from students $^{[8]}$. Although positive feedback on these evaluations was encouraging, I discovered that criticizing comments were most useful for identifying areas for improvement. These critiques were the primary way for me to discover what aspects of my pedagogy either displeased students or were possibly not compatible with a lesson. I consider it important to evaluate each critique carefully for validity and sincerity. Specifically, look for consistencies within comments, and carefully self-evaluate your pedagogy and course structure based on this student feedback. Some criticizing comments may appear ill-conceived, but I believe there is merit in carefully considering both the positive and criticizing comments from students. 


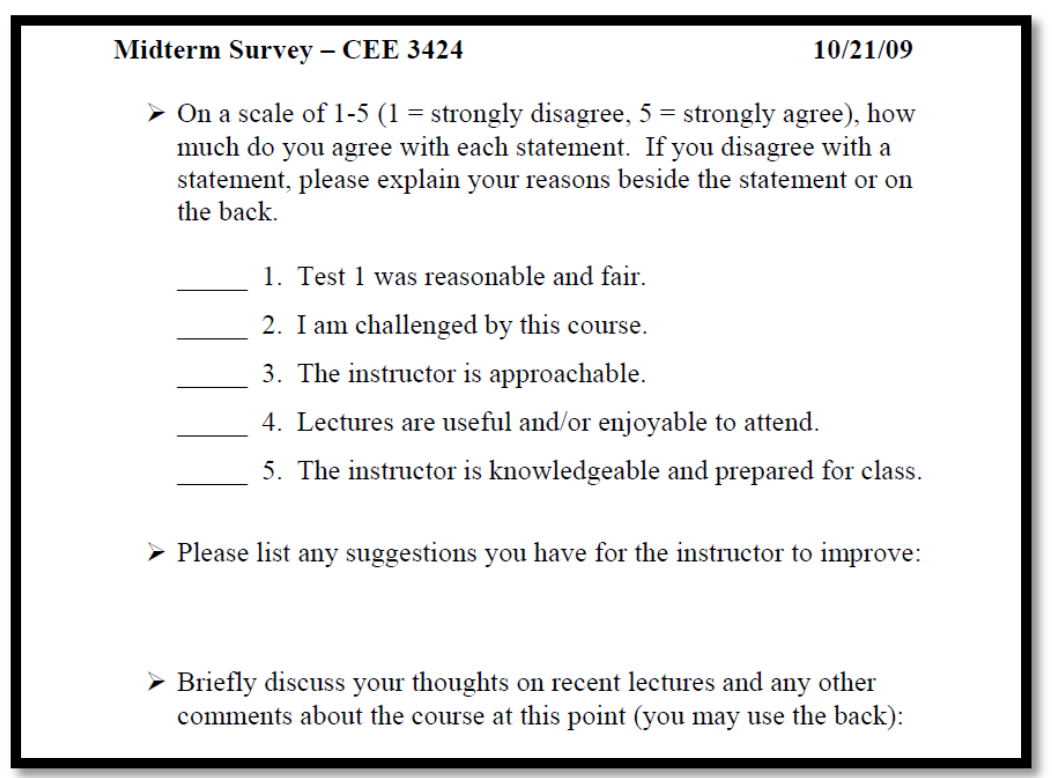

Figure 3: Sample evaluation used to reflect on pedagogy and course design.

\section{Using Reflection Practices}

In my experience, I found that reflection was an essential part of my improvement as an instructor. Several students in Reinforced Concrete Design noted on final course evaluations that they were pleased with changes made with the format of lectures mid-semester. These changes may not have taken place without listening to their feedback and reflecting on my abilities as an instructor. I encourage all graduate students and new instructors to make reflection a regular activity when they teach. Seek out multiple methods of reflection and evaluation to receive feedback and discover new methods of improvement. Specifically for graduate students interested in academic careers, reflection can also serve as a useful tool when formulating a teaching philosophy for the academic job search.

\section{Concluding Remarks for Graduate Student Instructors}

As a graduate student instructor, you should be confident to enter the classroom after preparing for this opportunity. You have been entrusted with an important responsibility, which should not be taken lightly. You should also use this opportunity to learn about yourself as an educator and mentor through sincere reflection and self-evaluation. Below is a list of final tips for graduate students entering the classroom as a new instructor:

- Discover your motivation for teaching and use this as a driving force to keep you energized throughout the duration of the course.

- Take advantage of opportunities to equip yourself with useful classroom skills.

- Prepare with intention, making an effort to make best use of your time and resources.

- Always consider your audience when planning, and consider alternatives in case a backup plan is necessary.

- Formulate reasonable expectations and knowledgeable assumptions.

- Take time to sincerely reflect on your pedagogy and evaluate yourself frequently. 
I encourage graduate students teaching for the first time to develop a support system of individuals they trust. Each time I have taught, I had a consistent support system of fellow graduate students and faculty members to discuss ideas and problems. This support system can help you through this experience both emotionally, mentally, and professionally. It is also very important to be intentional with your schedule, allowing enough time for both research and teaching duties. If you are not careful, your research progress can come to a screeching halt while you teach. Make the most of your experience while remembering to balance your student role with your newly appointed instructor role. Finally, be authentic in the classroom, and share in this experience with your students. This will not only be a learning experience for the students, but be prepared to learn more about yourself as you begin shaping the knowledge and perceptions of undergraduate students.

\section{Acknowledgements}

The author would like to acknowledge Carin Roberts-Wollmann, Thomas Cousins, and Holly Matusovich for serving as faculty mentors while teaching at Virginia Tech.

\section{References}

[1] Clemson University Academic Success Center (2012). Supplemental Instruction (SI). Retrieved from http://www.clemson.edu/asc/si/index.html.

[2] Tweed, R. G. and Lehman, D. R. (2002). Learning considered within a cultural context: Confucian and Socratic approaches. American Psychologist, 57(2), 89-99.

[3] Virginia Tech Charles E. Via, Jr. Department of Civil and Environmental Engineering (2012). Charles E. Via, Jr. Department of Civil and Environmental Engineering. Retrieved from http://www.cee.vt.edu/.

[4] Virginia Tech Department of Engineering Education (2012). Department of Engineering Education. Retrieved from http://www.enge.vt.edu/.

[5] Virginia Tech Department of Engineering Education (2012). Engineering Education Graduate Certificate. Retrieved from http://www.enge.vt.edu/Graduate/gradcert.html.

[6] Virginia Tech Graduate School (2012). Future Professoriate Graduate Certificate. Retrieved from http://graduateschool.vt.edu/academics/class_schedules/grad_courses/pfp_cert.html.

[7] Virginia Tech Faculty Development Institute (2012). Faculty Development Institute. Retrieved from http://www.fdi.vt.edu/.

[8] Wehlburg, C. (2002). More than a thermometer - using assessment effectively. In G. Wheeler (Ed.), Teaching and Learning in College: A Resource for Educators (4th Ed.) (177-199). Elyria, OH: Info-Tec.

[9] Whetten, D. A. (2007). Principles of effective course design: What I wish I had known about learnercentered teaching 30 years ago. Journal of Management Education, 31(3), 339-357.

[10] Scantlebury, M. M. G. (2008). Rules for the road (RFTR): Establishing a positive atmosphere for learning. Journal of Teaching in Travel and Tourism, 8(4), 395-400. 
[11] National Research Council. (2004). How people learn; brain, mind, experience, and school (Expanded Ed.). Washington, D.C.: National Academies Press.

[12] Prince, M. (2004). Does active learning work? A review of the research. Journal of Engineering Education, 93(3), 223-331.

[13] Roness, D. (2011). Still motivated? The motivation for teaching during the second year in the profession. Teaching and Teacher Education, 27, 628-638.

[14] Eccles, J. S., \& Wigfield, A. (2002). Motivational beliefs, values, and goals. Annual Review of Psychology, $53,109-132$. 